TAO, Vol. 12, No. 1, 179-194, March 2001

\title{
SUNYA Regional Model Simulation of Radiative Forcing and Climate Impact due to Contrails over Regions around Taiwan
}

\author{
Wei-Chyung Wang ${ }^{1, *}$, Wei Gong ${ }^{1}$, and Jen-Ping Chen ${ }^{2}$ \\ (Manuscript received 26 June 2000, in final form 22 February 2001)
}

\begin{abstract}
The effects of contrails on the radiative forcing and climate impact around Taiwan are studied using the State University of New York at Albany (SUNYA) regional climate model. The effects are calculated based on the contrail coverage, radiative properties of particle effective radius, and solar and longwave optical thickness as simulated from the National Taiwan University (NTU) contrail model (Chen et al. 2001). Both dissipating and persistent contrails are considered; for the latter, the diurnal variation of contrail coverage is also included.

For persistent contrails with diurnal variation, the daily mean solar and longwave radiative forcing at the top of the atmosphere are calculated to be 5.8 and $2.1 \mathrm{~W} \mathrm{~m}^{-2}$, respectively, while the corresponding values on the surface are 4.9 and $0.19 \mathrm{~W} \mathrm{~m}^{-2}$; the radiative forcing without diurnal cycle is about $2 / 3$ of these estimates. For dissipating contrails, the radiative forcing is much smaller because of smaller optical thickness. The simulation results also indicate that the spatial pattern of the radiative forcing follows closely the spatial distribution of the contrail coverage. In addition to the radiation forcing, an ensemble of model simulations was also conducted to examine the climate impact. As expected, the presence of contrails leads to a warming of the contrail layer due to absorption of the solar radiation and trapping of the upwelling longwave radiation. However, the radiation-induced warming signal, although robust, is small when compared with the inherent temperature variability attributed to other dynamic factors. A small cooling of the surface is also simulated.
\end{abstract}

(Key words: Contrail climatic effects, Radiative forcing, Regional climate model)

\footnotetext{
${ }^{1}$ Atmospheric Sciences Research Center, State University of New York at Albany, New York, U.S.A

${ }^{2}$ Department of Atmospheric Sciences, National Taiwan University, Taiwan, ROC

${ }^{\star}$ Corresponding author address: Prof. Wei-Chyung Wang, Atmospheric Sciences Research Center, State University of New York at Albany, New York, USA; E-mail: wang @ climate.cestm.albany.edu
} 


\section{INTRODUCTION}

Aircraft flying at cruising altitudes of 8 to $18 \mathrm{~km}$ emit pollutants consisting of $\mathrm{CO}_{2}, \mathrm{NO}_{x}$, water vapor, soot and sulfate particles which can affect radiative forcing directly through attenuation of solar and longwave radiation, and indirectly through modifying the chemical properties of the radiatively-important atmosphere constituents $\left(\mathrm{O}_{3}\right.$, the formations of contrails and cirrus clouds) with subsequent climate implications. On the global and annual mean basis, both effects are small when compared with other radiative forcing of anthropogenic origin (e.g., the greenhouse gases), but the values on the regional basis for short time scales may be large, although the uncertainty is also large.

As summarized in IPCC (1999), for all 1992 aviation, the total radiative forcing for the surface-troposphere climate system from aircraft emissions (gases and aerosols) was estimated to be $0.05 \mathrm{~W} \mathrm{~m}^{-2}$, about $3.5 \%$ of total anthropogenic radiative forcing (versus pre-industrial atmosphere) of $1.4 \mathrm{~W} \mathrm{~m}^{-2}$ for combined greenhouse gases and aerosols (and $2.7 \mathrm{~W} \mathrm{~m}^{-2}$ for greenhouse gases alone). The individual contributions of aircraft-induced radiative forcing (in $\left.\mathrm{W} \mathrm{m}^{-2}\right)$ are: $\mathrm{CO}_{2},(0.018), \mathrm{NO}_{\mathrm{x}}\left(0.023\right.$; via $\mathrm{O}_{3}$ changes), and $\mathrm{NO}_{\mathrm{x}}\left(-0.014\right.$; via $\mathrm{CH}_{4}$ changes), contrails (0.02), $\mathrm{H}_{2} \mathrm{O}(0.002)$, sulfate aerosol (-0.003; direct effect), and soot (0.003). Changes in cirrus clouds in the upper troposphere caused by aircraft emissions may potentially induce large radiative forcing, up to $0.04 \mathrm{~W} \mathrm{~m}^{-2}$. Projection of subsonic fleet growth to 2015 was also used to estimate the radiative forcing attributed to aircraft emissions. The total estimated radiative forcing is $0.11 \mathrm{~W} \mathrm{~m}^{-2}$, about $5 \%$ of projected radiative forcing from all other anthropogenic emissions for that year. The IPCC report also considered the addition of a fleet of. high-speed civil transport (HSCT) supersonic aircraft replacing part of the subsonic air traffic. However, this will further increase the total radiative forcing because the HSCT alone will contribute significantly more, by about a factor of five, than the displaced subsonic aircraft because of the added emission of water vapor.

Note that the radiative forcing includes global and annual mean values, and the regional and seasonal variations are quite large, sometimes up to a factor of 2 to 3 . For example, Wang et al. (2000) investigated the perturbations to atmospheric gas species from aircraft emissions in 1992, 2015, and 2050, the base years in IPCC (1999). The global average $\mathrm{NO}_{\mathrm{x}}$ emission based on the IPCC-IS92a scenario for the three years were calculated to be $0.50,1.24$, and 2 . $30 \mathrm{Tg}(\mathrm{N}) / \mathrm{yr}$, respectively. The model year 2015 was chosen to illustrate the impact of future aircraft activity, in particular the supersonic aircraft. In the dry stratosphere, the increase of water vapor due to supersonic aircraft emissions can be significant, with a maximum increase of between $10 \%$ and $20 \%$ at middle to high latitudes. $\mathrm{O}_{3}$ changes show an increase in the troposphere and a decrease in the stratosphere with a strong latitudinal dependence of the altitude of the sign change. The calculated increases in tropospheric $\mathrm{O}_{3}$ are between 5 and 8 ppbv. Maximum changes of $\mathrm{O}_{3}$ are found at $320 \mathrm{hPa}$, and the changes exhibit strong geographical distribution, with most of the changes coinciding with the major flight routes in the Northern Hemisphere, although the peak values occur at the subtropics. For radiative forcing, the calculations suggest that the global and annual radiative forcing due to subsonic aviation is $0.036 \mathrm{~W} \mathrm{~m}^{-2}$. The combined fleet of subsonic and supersonic aircraft provides a radiative forcing of $0.055 \mathrm{~W} \mathrm{~m}^{-2}$. Note that the water vapor emission from supersonic aviation plays an 
important role. Although the $\mathrm{O}_{3}$ effect on the annual and global radiative forcing is small, the regional effect is much larger, up to $0.15 \mathrm{~W} \mathrm{~m}^{-2}$, with strong seasonal variations.

When the ambient air is sufficiently cold, visible line-shaped contrails can form behind the aircraft as a result of water vapor emission and formation of ice crystal by instant freezing of the water drops that formed. IPCC (1999) estimated that in 1992 the contrail on the annual basis covered $0.1 \%$ of the Earth's surface with large regional values; for example, it amounted to $0.5 \%$ on average over central Europe during the daytime. Perhaps more importantly, the contrail coverage was projected to grow to $0.5 \%$ by 2050 , with a much larger increase over East Asia. Persistent contrails often develop into more extensive contrail cirrus in ice-supersaturated air masses. Available studies (e.g., Minnis et al. 1999) indicate that increases in cirrus cloud coverage have been found to be positively correlated with aircraft emissions. Because of their optically thin nature, the contrails may behave like thin cirrus and thus add a warming effect to the local temperature and the atmosphere-surface climate system. For a 0 . $1 \%$ global mean contrail coverage and 0.3 visible optical depth, the global radiative forcing is calculated to be $0.02 \mathrm{~W} \mathrm{~m}^{-2}$ with much larger values, up to $0.7 \mathrm{~W} \mathrm{~m}^{-2}$, over heavy air traffic areas.

In this study, we focus on the effects of contrails on the radiative forcing and its climate implications over the surrounding areas of Taiwan. As shown in Fig. 1, the region is a central part of the major air traffic route involving Japan, Korea, Eastern China, Taiwan, and Hong Kong down to Southeast Asia (see Lin et al. 2001 for details). It is one of the three heavily traveled routes (IPCC 1999), and the fastest growing one because of the increasing population and economic activity in the last decades. It is expected that the pace of growth there will continue in the coming decades. In addition to the radiative forcing, we also examine the potential climate implications. Note that because of the short life cycle of the contrails, the study emphasizes on the effects on the diurnal variations and daily time-scales. Section 2 describes the approach of using the contrail information in the regional climate model to simulate the radiative forcing and climate implications while the simulation results are presented in Section 3. Section 4 summarizes the conclusions, and discusses future research needs.

\section{MODEL AND EXPERIMENT DESIGN}

We used the SUNYA regional climate model (RCM) to simulate the radiative forcing and to illustrate the potential impact on climate due to contrails. The model domain is $\left(15 \sim 45^{\circ} \mathrm{N}\right.$; $100 \sim 140^{\circ} \mathrm{E}$ ) with a $60-\mathrm{km}$ horizontal resolution ( $65 \times 85$ grid points) and 23 vertical levels. The model has been demonstrated to simulate realistically some of the important components of the East Asia monsoon, such as the upper-level westerly jets, middle-level Western Pacific subtropical high, and low-level southwest flow (Wang et al. 2000; Gong and Wang 2000). A more realistic soil-vegetation model with consistent boundary layer (Xue et al. 1996) and a radiation package (Kiehl et al. 1996) of the National Center for Atmospheric Research (NCAR) Community Climate Model version 3 (CCM3) were recently adopted to treat more accurately the atmosphere-land surface interactions. As a result, simulations of the diurnal cycle of surface air temperature and precipitation are substantially improved. 


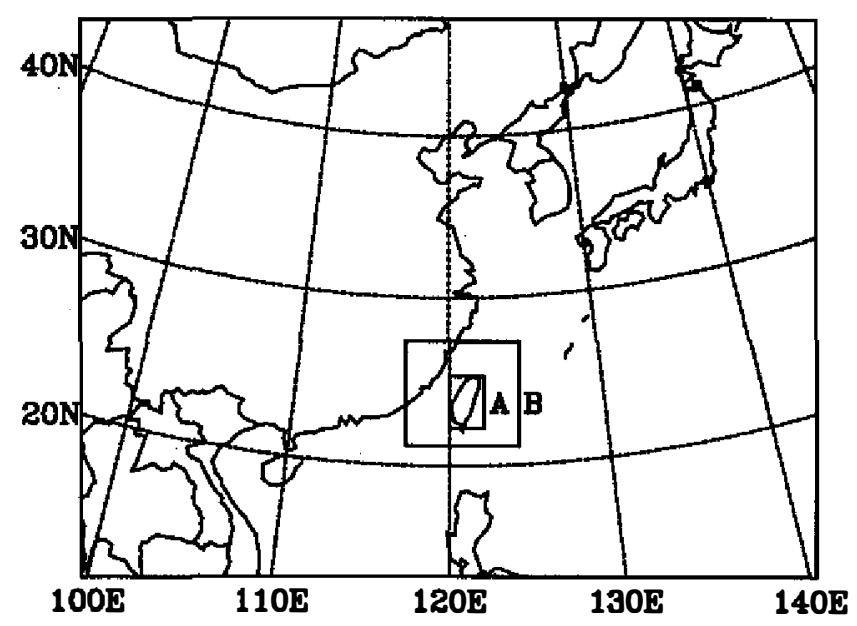

Fig. 1. Domain of model simulation, and the two regions surrounding Taiwan for studying the effects of contrails on the radiative forcing and the climate responses. The inner and outer regions are designated as A and B, respectively.

In addition, the RCM model treatment of cloud-radiation interaction is further refined for consistency. Specifically, the cloud liquid/ice water contents (CWC), based on the explicit moisture scheme \#3 of Reisner et al. (1998), are coupled to the cloud optical thickness for subsequent radiation calculations. The cloud coverage is diagnosed from relative humidity and convective precipitation for various cloud types (Liang and Wang 1995; Gong and Wang 2000). Further modification of cloud formations in regions with downward motion (e.g., Western Pacific subropical high) is applied over the oceans to reduce excessive cloud coverage.

The simulation of contrail radiative effects requires the information of horizontal and vertical distribution of contrail radiative properties as a function of time. Clearly, proper meteorology (e.g., temperature, moisture and circulation) is needed to provide a favorable condition for the formation of contrails. However, as a first approximation, we limit our study to the use of prescribed information simulated from a contrail model (Chen et al. 2001). We describe below the incorporation of the information into the regional model for simulating the radiative forcing and the subsequent climate implications.

Basically, the contrail model provides the horizontal distribution of four parameters: cloud coverage, mean particle effective radius, and solar and longwave optical thickness around the Taiwan area. We assume that the contrails vertically occupy one full model layer, located at $10-12 \mathrm{~km}$ (around $200 \mathrm{hPa}$ ) in the upper troposphere, where the analyses of Chen et al. (2001) show the most occurrences. These parameters are then mapped onto the regional climate model's grid points with contrails (see region B in Fig. 1) using a distance weighted interpolation scheme. Note that the spatial resolution of the data produced by the contrail model is 5 $\mathrm{km}$, and the interpolation will certainly smooth the radiative properties in the areas where large gradient exists. However, we expect that the effect of the interpolation is small simply because both the optical thickness and the subsequent radiative forcing are small, as will be 
shown in next Section. We also consider the diversity of contrail properties by adopting the classification of Chen et al. (2001), who categorized contrails in the Taiwan region into 12 types according to the ambient temperature and relative humidity with respect to ice. In this classification, types 1-9 are for dissipating contrails and types 10-12 are for persistent contrails. The averaged distribution of contrail coverage (not shown) for these contrail types indicates that the contrail pattern over Taiwan reflects closely the air traffic pattern (see Chen et al. 2001 for more discussions). We assume that contrails exist by themselves without preexisting cirrus clouds (see Schroder et al. 2000).

The contrail model simulates only the optical thickness and effective particle radius for both the solar and longwave spectra (see below). However, additional parameters of single scattering albedo and asymmetry factor are needed for radiation calculation. For solar radiation, we use the empirical expressions for ice cloud that relate the single scattering albedo and asymmetry factor to the effective particle radius. We expect that this treatment is adequate since the solar radiation for contrails is dominated by the optical thickness and the single scattering albedo and asymmetry factor play relatively minor roles. For longwave radiation, we use the optical thickness to calculate the contrail emissivity.

The contrail coverage, particle radius, and solar and thermal optical thickness averaged over two regions (A and B) are shown in Fig. 2 for the twelve contrail types. It can be seen that the values are larger for region A because of heavier air traffic frequency. The contrail coverage ranges from 2 to $12 \%$, while the effective particle radius is about a few micrometers, all consistent with observations (Schroder et al. 2000). For persistent contrails, the solar optical depth is about 0.6-0.8, which is an order of magnitude larger than the longwave optical depth. Note that here the contrail properties of type 11 are close to the average values of types 10-12. In the following, type 11 is chosen to represent the persistent contrail.

The potential effects of contrails on the regional climate are studied by comparing the changes that would occur with as opposed to without contrails in the following two parameters: the radiative forcing and the climate response. The former is the changes in the radiative fluxes either at the top of the atmosphere (TOA) or on the surface after the contrail layer is inserted, while the latter is the subsequent responses of the climate state (e.g., temperature). Consequently, the climate response includes the various feedbacks of the atmosphere-surface system to the radiative forcing caused by the presence of contrails.

It is quite clear that there is a strong diurnal variation in the effect of contrails, attributed to the diurnal variation of the TOA incoming solar radiation, the meteorological conditions, and the contrail coverage itself due to flight scheduling. For example, Fig. 3 shows the diumal variation of the aircraft flight frequency, characterized by a peak of about $7 \%$ at 8 am, a relatively small variation around 5 6\% throughout the daytime and then a sharp drop-off after 9 $\mathrm{pm}$. The diurnal contrail coverage variation is calculated based on the daily mean value weighted by the flight frequency (see Chen et al. 2001 for more discussion). Consequently, the contrails occur after sunise, exhibit substantial fluctuations during the rest of the day, and disappear at night. Therefore, we study the radiative forcing and climate response with and without including the diurnal cycle.

The integration of RCM requires us to determine the driving fields (initial and lateral boundary conditions) in order to conduct simulations (Wang et al. 2000). In the present study, 

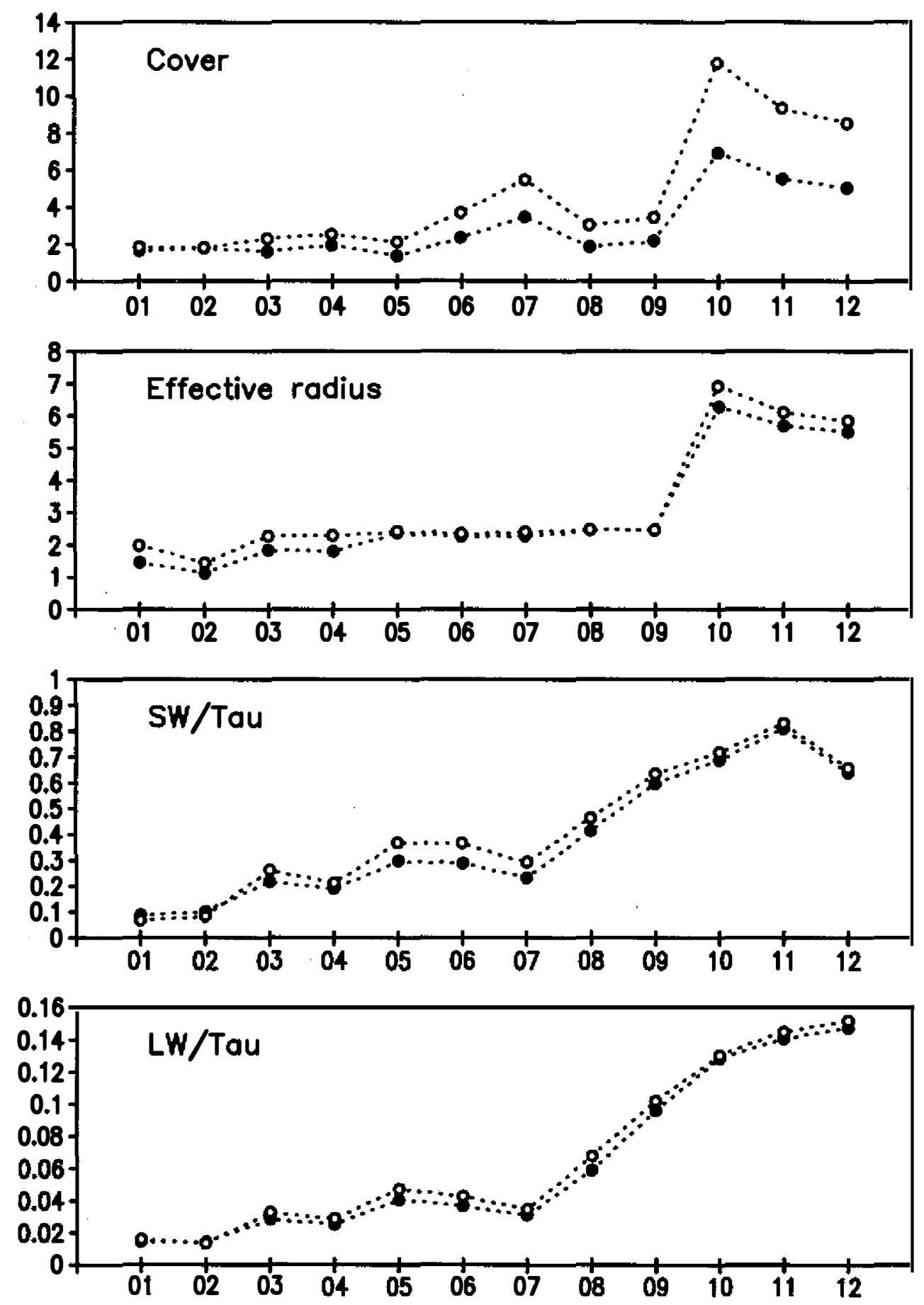

Fig. 2. Diumal cycle of the contrail frequency of occurrence (\%). 


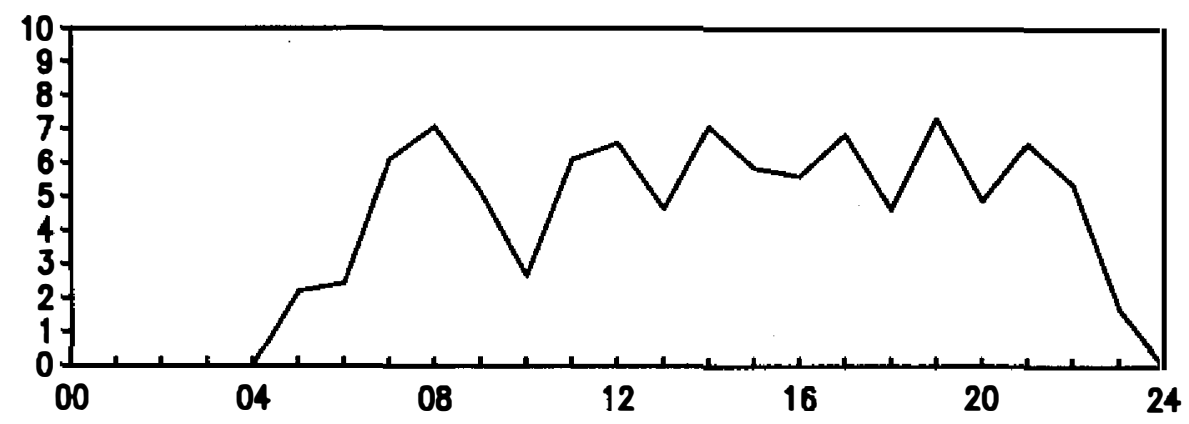

Fig. 3. Contrail model simulated mean contrail characteristics of: (a) coverage (\%), (b) particle effective radius $(\mu \mathrm{m})$, (c) mean shortwave optical thickness, and (d) mean longwave optical thickness. Values are the means over region A (open circle) and region B (solid circle). Twelve types are simulated with \#1-9 for dissipative contrails and \#10-12 for persistent contrails.

they are generated from European Center for Medium-Range Weather Forecasts (ECMWF)Tropical Ocean Global Atmosphere (TOGA) objective analysis (horizontal resolution of $2.5^{\circ}$ $\times 2.5^{\circ}$ ). The ECMWF-TOGA analysis was interpolated onto the RCM's grid points and vertical levels, and updated twice a day. The sea surface temperature (SST) of the National Center of Environmental Prediction (NCEP) (with the same horizontal resolution of TOGA) was used at the oceanic grid points. The SST data was also interpolated onto the RCM gridpoints with updates twice a day.

For radiative forcing, we performed $2 \times 12 \times 24$ calculations for each time step corresponding to: with and without diurnal variation of contrail coverage for the twelve contrail types at each hour of the day (with different solar zenith angle). The sensitivity experiments are compared against the respective reference calculations without including the contrail. All calculations use the identical initial and lateral boundary conditions at 0:00 GMT of May 1, 1998 so that the radiative forcing at each hour can be consistently compared.

\section{RADIATIVE FORCING}

As mentioned above, the radiative forcing is defined as the difference of radiative fluxes between experiments with and without contrails. The radiative forcing is calculated at both TOA and surface, to estimate the contrail effect on the surface-atmosphere and surface, respectively. Here, positive solar radiative forcing means that more solar flux leaves the system (i.e., TOA and surface), resulting in a cooling effect. However, positive longwave forcing suggests a more effective trapping, yielding a warming effect. The daily solar and longwave radiative forcing, which are averages at each hour, are calculated for the twelve contrail types over the two regions A and B shown in Fig. 1. Note that these values are daily, regional mean radiative forcing, and therefore are much smaller than those listed in Table 2 of 
Chen et al. (2001), which gives the values for the contrails individually.

In the presence of contrail, the solar radiative forcing is positive (i.e., increased upward solar flux) at both TOA and surface, shown in Fig. 4a and 4c, respectively. The maximum forcing is calculated to be 5.8 and $4.9 \mathrm{~W} \mathrm{~m}^{-2}$, respectively at TOA and surface, for contrail type 10 with diumal variation of contrail coverage. The positive solar radiative forcing is expected because the contrail will reflect solar radiation just like a natural cloud, and thereby induce a cooling into the atmosphere below the con rail layer. Furthermore, the solar radiative forcing at the surface is not substantially different from that at TOA, indicating that absorption by the contrail layer is small. The diumal variation of the contrails also affects significantly the solar radiative forcing. For example, for persistent contrail (types 10-12), the radiative forcing can be enhanced by about $40 \%$ when diurnal change of contrail coverage is included in the simulations. The primary reason for this is that the diurnal cycle of the solar radiation coincides, to some extent, with that of contrail coverage during the daytime so that the contrail effect is substantially enhanced. Note that, although persistent contrails have rather long lifetimes, individual contrails do not stay long in the model domain because of advection by the strong westerlies.

For the longwave radiative forcing, the maximum daily mean values are 2.1 and 0.19 $\mathrm{Wm}^{-2}$, respectively, at TOA and surface for type 10 . The positive forcing at TOA is caused by the "greenhouse effect", i.e., the contrails located at $200 \mathrm{hPa}$ with colder temperature (than the surface) and thus absorb the warmer upwelling surface emissions and re-emit at local temperatures. Thus, the con will will induce a warming effect into the atmospheric column inside and below the contrail layer. However, two features are different when compared with the solar radiative forcing. First, the diurnal variation of the longwave radiative forcing is small, partly due to the use of the same atmospheric temperature in the simulations. Nevertheless, the diurnal variation of the temperature distribution will not change the characteristics very much. Second, the longwave radiative forcing at TOA is much larger (about 10 times) than that at surface, indicating that the warming inside the contrail layer and the layers immediately below the layer account for much of the trapped longwave radiation energy. More discussion of this aspect will be given below.

The solar and longwave radiative forcing also exhibit strong regional variation, as can be seen in Fig. 4a-d. The radiative forcing over the smaller region A is twice as large as that over region $\mathrm{B}$, both at TOA and on the surface. In addition, the radiative forcing for the individual contrail types follow closely with the contrail properties shown in Fig. 2a-d and, as will be shown later, both solar and longwave radiative forcing are dominated by the contrail coverage. As suggested by Figs. 2 and 4, type 11 is representative of the persistent contrails. Although type 11 con trail occur only on May 7-9 according to Chen et al. (2001), we use this contrail type to illus ate the spatial pattern and to provide an upper-limit for the effect of the radiative forcing and climate responses.

Figure 5a shows the distribution of contrail coverage over region B. There is a maximum of about $10 \%$ in the south of Taiwan, reflecting both the favorable atmospheric conditions for contrail formation and major air traffic routes. The contrail coverage decreases toward Mainland China, mainly due to insignificant air traffic at the contrail-forming altitudes across the Taiwan Strait (Lin et al. 2001). The contrail coverage can be up to $10 \%$ at its maximum, with 

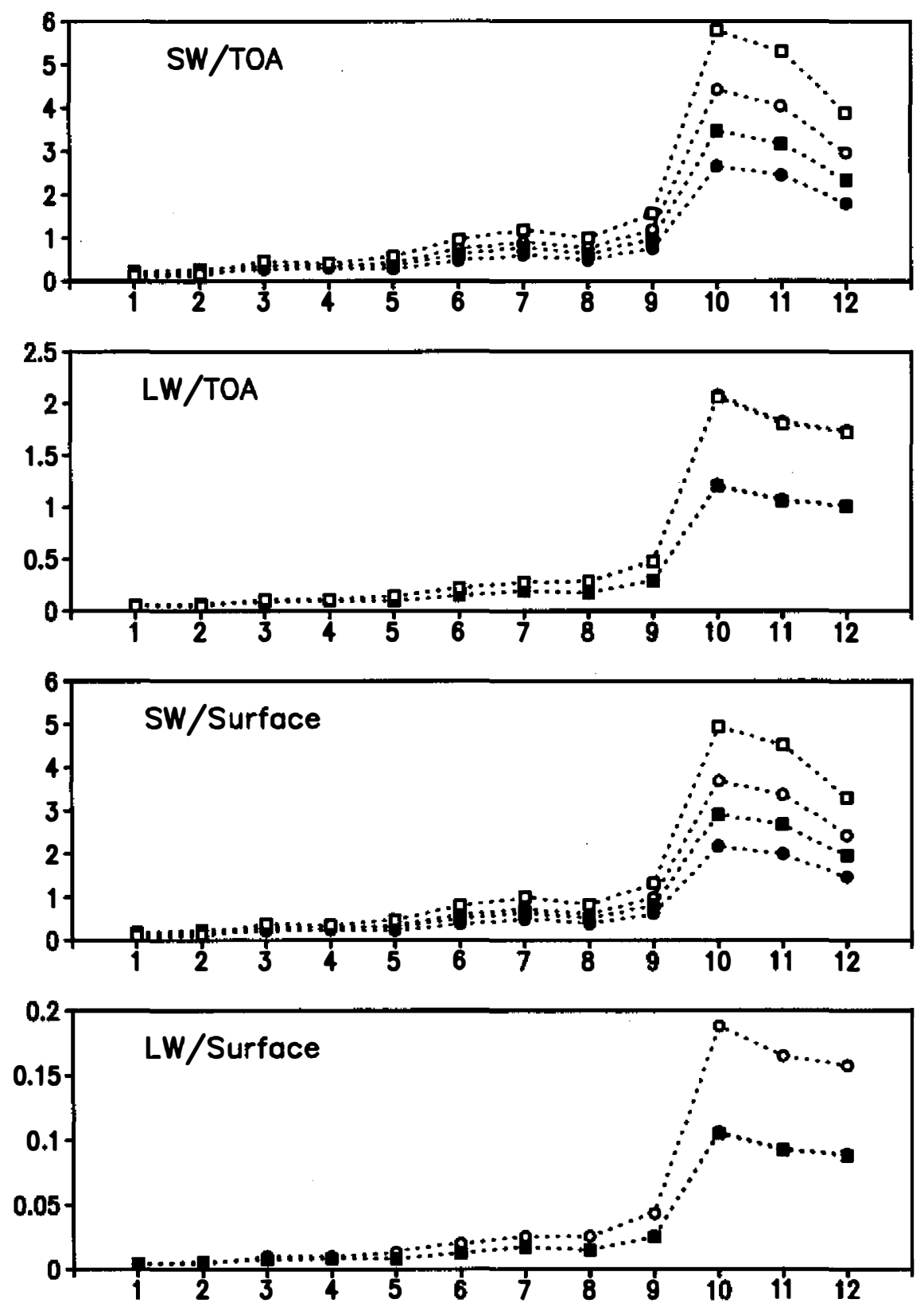

Fig. 4. Changes in mean radiative flux ( $\mathrm{W} \mathrm{m}^{-2}$ ) caused by the presence of contrails for the twelve types. Values are for shortwave (SW) and longwave (LW) radiation at the top of the atmosphere (TOA) and on the surface. Squares and circles correspond to "with" and "without" the diurnal cycle of the contrail coverage (Fig. 2), while open and solid symbols represent regions $\mathrm{A}$ and $\mathrm{B}$, respectively. 

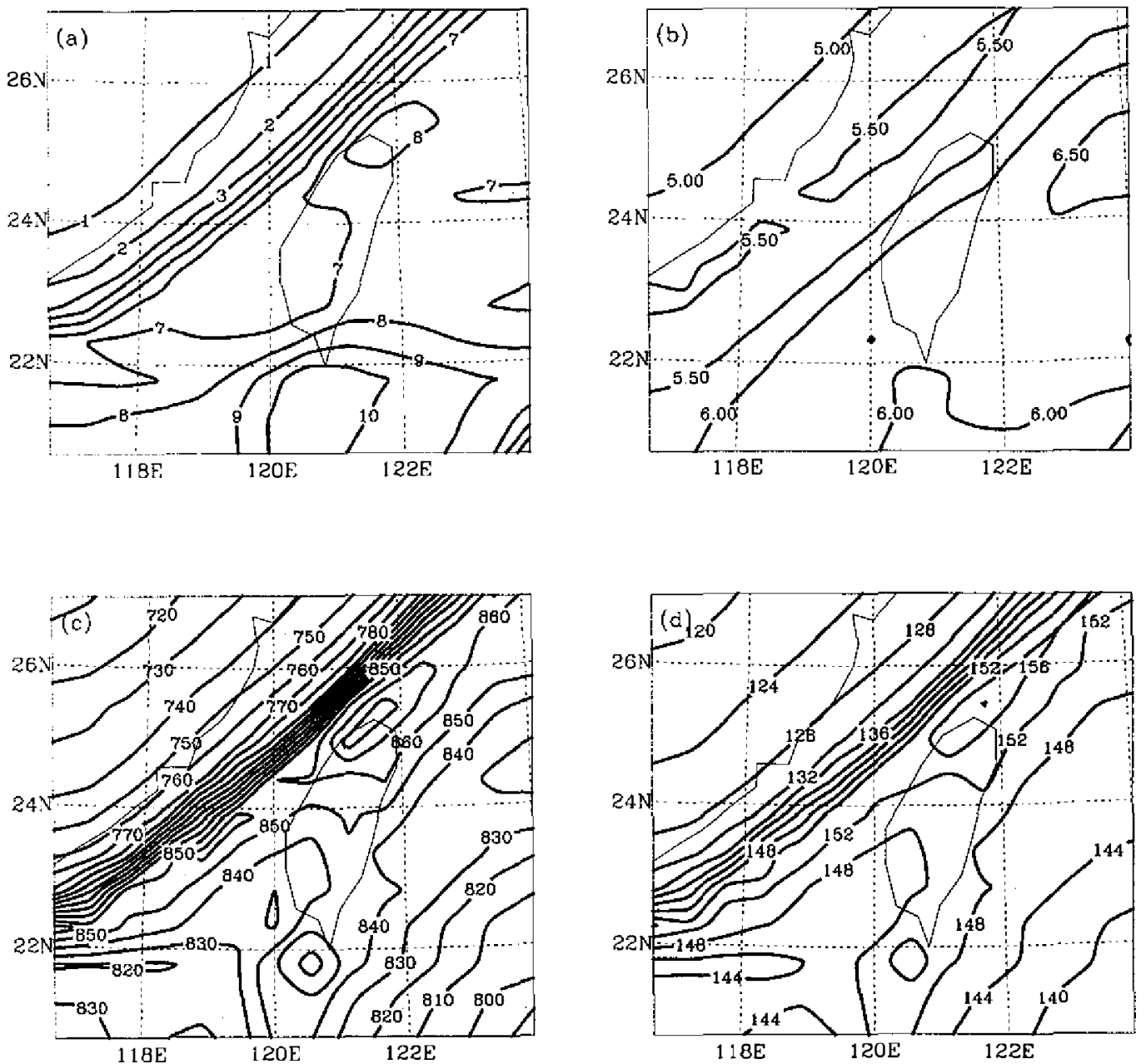

Fig. 5. Contrail model simulated geographical distribution of contrail characteristics: (a) coverage (\%), (b) particle effective radius $(\mu \mathrm{m})$, (c) mean shortwave optical thickness (x1000), and (d) mean longwave optical thickness $(\mathrm{x} 1000)$. Values are for the persistent contrail type \#11 shown in Fig. 3.

mean value of a just a few percent. As shown in Figs. 5b-d, the pattern of southwest-northeast orientation also exists in the effective particle radius, and in solar and longwave optical thickness. Despite small differences in the central location of the axis among different properties, this pattern also coincides with the air traffic pattern in this area. The particle effective radius is generally a few micrometers, consistent with observations (Schroder et al. 2000). The range of values for optical thickness is $0.72-0.88$ and $0.116-0.150$, respectively, for solar and longwave radiation. This contrast in spectral distribution is related to the simulation results in that most of particles in the contrails are $5 \mu \mathrm{m}$ or smaller in size (Lin et al. 2001), which yields a larger 
optical depth in the solar spectrum.

Figures 6a-b show the spatial pattern of daily mean solar and longwave radiative forcing when the diurnal variation of contrail coverage is considered. The patterns for both solar and longwave radiative forcing show a similar pattern as the contrail coverage. For example, the maximum radiative forcing in the south of Taiwan and the moderate gradient from northwest to southeast coincide with that of contrail coverage spatial pattern. Although there are similarities between the radiative forcing and solar and longwave optical thickness, the detailed distribution of radiative forcing cannot be explained simply by optical thickness. For example, as shown in Fig. $5 \mathrm{c}$, the largest solar radiative forcing occurs in the south of Taiwan, while the maximum solar optical thickness is located in the north of Taiwan. Similarly, the maximum longwave optical thickness (Fig. 5d) in the band extending from southwest to northeast does not match the band of strong longwave radiative forcing. So, the contrail coverage appears to
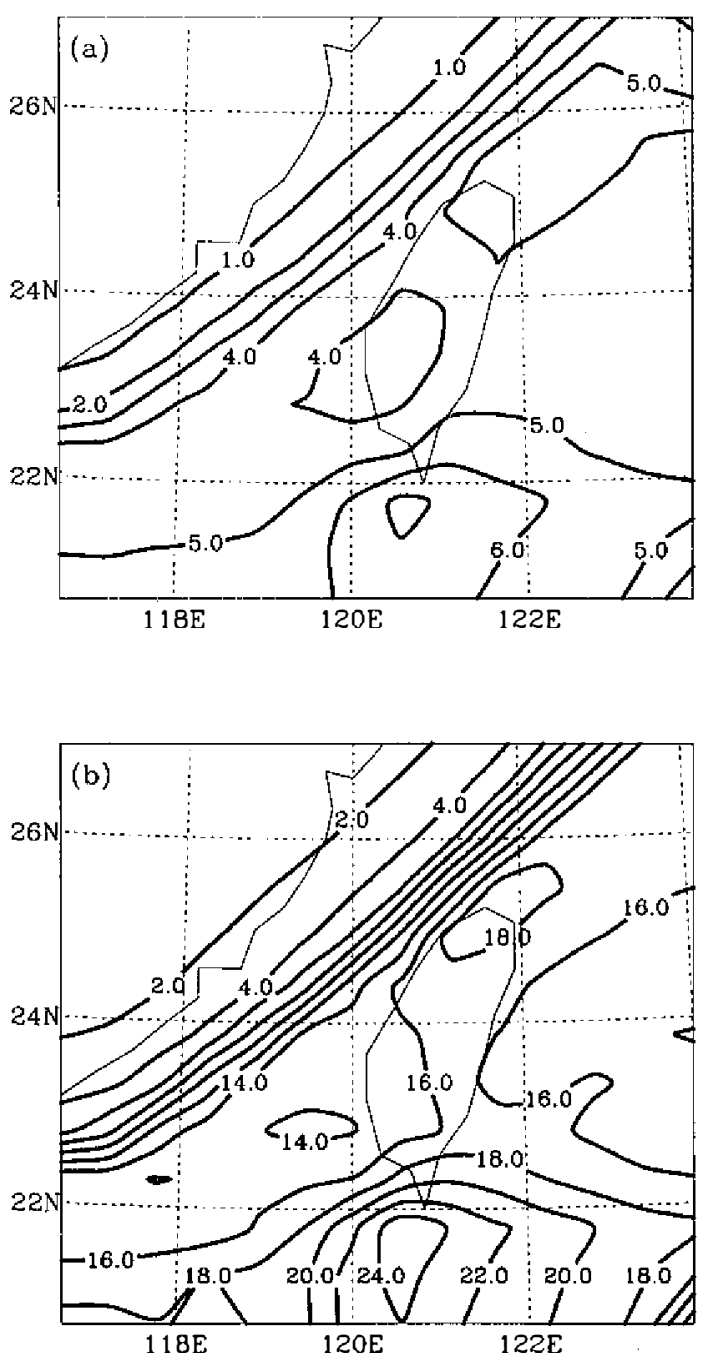

Fig. 6. The geographical distribution of changes in daily mean, upward net radiative flux $\left(\mathrm{W} \mathrm{m}^{-2}\right)$ at the top of the atmosphere. Values are (a) shortwave and (b) longwave (x10) fluxes for contrail type \#11 with diurnal cycle of the contrail coverage. 
be the dominant factor in determining the pattem of radiative forcing. Note that solar radiative forcing has a linear dependence on the optical thickness and contrail coverage, while the longwave radiative forcing depends more on the contrail coverage than the optical thickness. It is thus apparent that the distribution of contrail coverage has a high degree of association with the radiative forcing, because the other contrail properties are more uniformly distributed.

It is also worthwhile to illustrate the diumal variation of radiative forcing because of the strong diurnal cycle of incoming solar radiation and contrail coverage (Chen et al. 2001). Figure 7 shows the diurnal variation of solar and longwave radiative forcing at TOA and on the surface in the two regions for type-11 contrails. First, we find that, although the solar radiative forcing disappears at sunrise and sunset, both solar and longwave radiative forcing generally follow the variation of contrail coverage (Fig. 2). This result is consistent with our finding that contrail coverage dominates the radiative forcing. Thus, the amplitude of diurnal cycle in contrail coverage can be used to evaluate the radiative forcing if the daily mean radiative forcing is known. Second, we also find that the instantaneous radiative forcing can be about 2-4 times as large as that of the daily mean (see type 11 in Figs.7 and 4). Finally, the relationship of radiative forcing between TOA and surface is similar to that of the daily mean, as shown in Fig. 4a-d, for both solar and longwave radiation.

\section{CLIMATE IMPACT}

As discussed in the introduction, radiative forcing is a commonly used parameter to rank the relative effects of different causes for climate changes. The parameter is simple and can provide a reasonable basis of comparison of potential changes in the global and annual mean surface temperature (IPCC 1996, 2001). However, it is not adequate for examining the regional climate changes, even for uniformly distributed greenhouse gases (Wang et al. 1991). Consequently, the parameter may also provide misleading climate impact information of contrails that exhibit sung spatial and temporal variations. In this regard, we conduct the following model experiments to examine the potential climate impacts due to contrails.

Because of the large model inherent variability (the noise) in our regional model (Gong and Wang 2000), an ensemble simulation approach was adopted. Three sets of model simulations were carried out with initial conditions corresponding, respectively, to 0:00 GMT (8:00 am local time) of May 1, 1998, and one and two days earlier than May 1. For each set, three runs were made-a control run without contrails, and two perturbed runs with and without the diurnal variation of contrails. To maximize the radiative forcing (the signal), we use the type11 persistent contrails and assume a clear sky condition in the one-day (May 1) simulation for both the control and perturbed runs. The difference (in the climate parameters) between control and the corresponding perturbed run represents the model signal, while the difference between the three control runs provides the model noise. Because of its relatively larger signal, the case with diurnal variation of persistent contrails is used in the discussion here.

The mean temperature changes inside the contrail layer and in the layer immediate above for region A (see Fig. 1) are shown in Fig. 8. Because of the absorption of both the solar radiation and the upwelling longwave radiation, the contrail layer temperature shows a small 

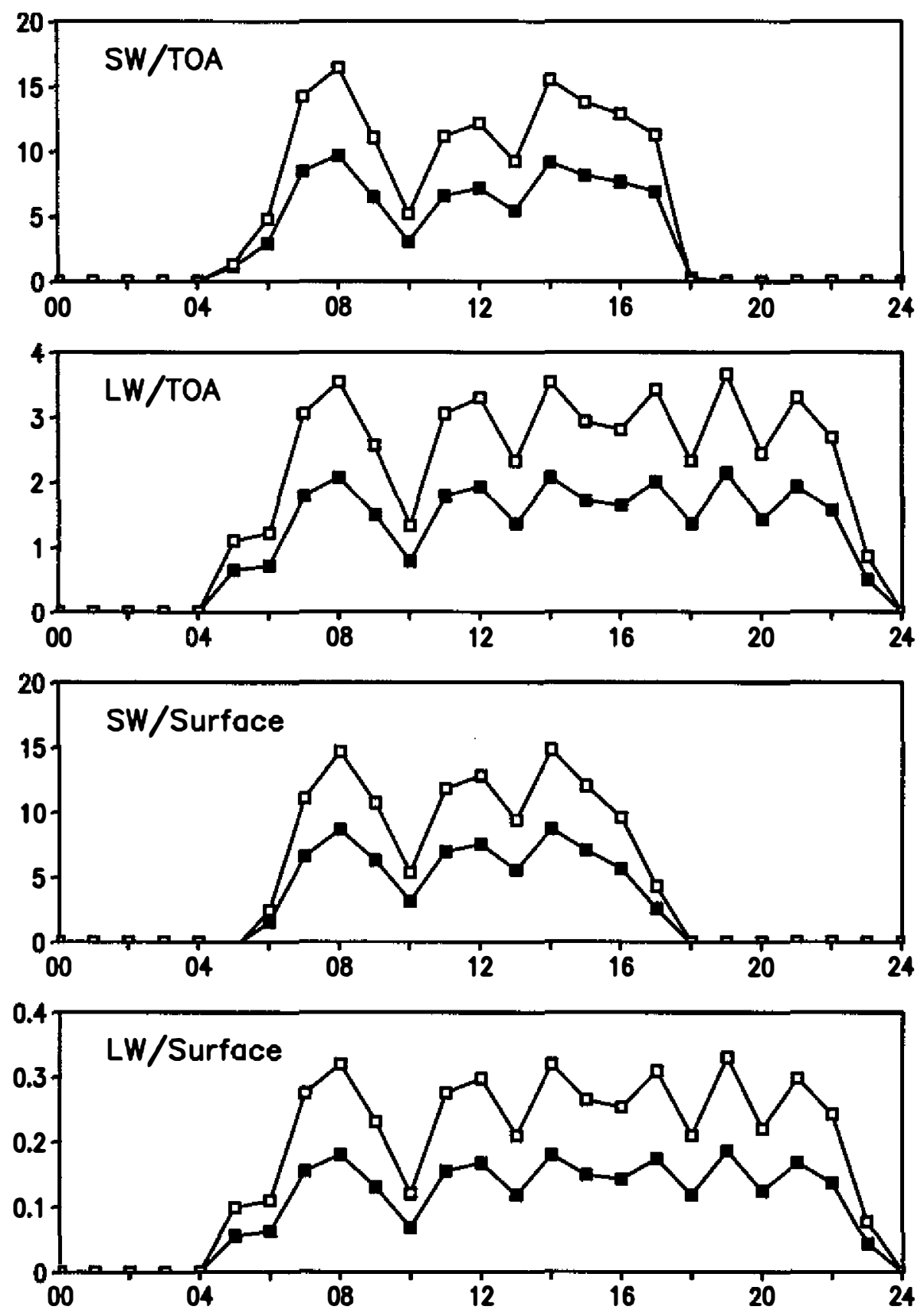

Fig. 7. Diumal variation of changes in net radiative flux $\left(\mathrm{W} \mathrm{m}^{-2}\right)$ at the top of the atmosphere (TOA) and on the surface due to presence of contrails. Values are for upward shortwave (SW) and downward longwave (LW) fluxes. Open and solid symbols represent regions A and B, respectively. 
Fig. 8. Diurnal variation of mean

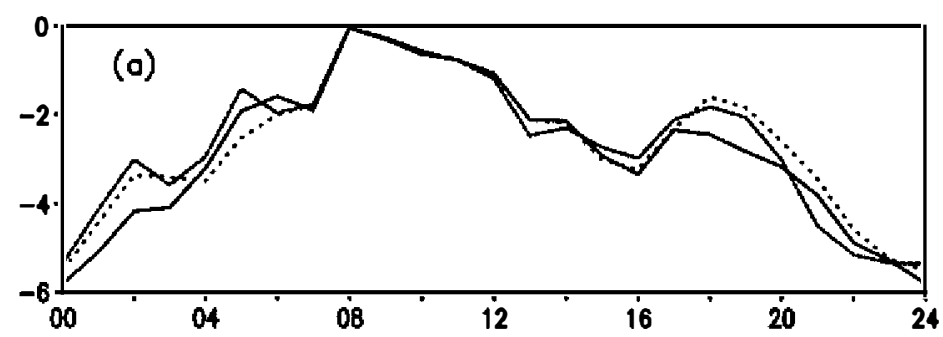
temperature $\left(\mathrm{x} 100^{\circ} \mathrm{C}\right)$ averaged over region $\mathrm{A}$ for (a) layer above and (b) inside the contrail layer located at $11-12 \mathrm{~km}$. Three sets of ensemble experiments are conducted, with initial conditions corresponding, respectively, to May 1, 1998 (solid), one-day (dotted), and two-days (dashed) earlier. The contrails were inserted at hour 08 (local time) of May 1 for all three experiments.

warming throughout the day with a daily mean warming of $0.03^{\circ} \mathrm{C}$. The diurnal variation of the warming, dominated by the solar radiative forcing, has a maximum of $0.08^{\circ} \mathrm{C}$ in the late afternoon. For the layer immediately above the contrail, a cooling is simulated mainly because of the blocking of the upwelling surface longwave radiation (by the contrail) from reaching the level; a maximum cooling of $0.06^{\circ} \mathrm{C}$ is calculated at midnight. Note that, as shown in Fig. 8 , all three sets of simulations show consistent signals, indicating the robustness of the results. However, the small temperature changes raise the issue of the signal-to-noise ratio of the contrail effect. We have compared the three control runs without the contrails, which provide indications of the model variability. As expected, the temperature variability is large (cf. Gong and Wang 2000). In the present study, the maximum noise during the May 1 simulation is found to be about $0.35^{\circ} \mathrm{C}$, which is much larger than the maximum warming of $0.08^{\circ} \mathrm{C}$ inside the contrail layer. These results clearly illustrate that the contrails can provide a heating source to the local temperature, although given the contrail properties used here the warming itself is small. Note that the warming caused by the contrails is also much smaller than the temperature variability attributed to other dynamic heating sources.

The presences of contrails cool the surface temperature, although the cooling is even smaller, an order of magnitude smaller than the cooling of the layer above the contrail. Two factors contribute to the small cooling. The first is that the cooling caused by the decreased downward solar radiation reaching the surface is offset to some extent by the warming due to enhanced downward longwave radiation from the contrail layer, and the other factor is the fixed sea surface temperature in the simulations. The latter factor is reflected in the results that the surface cooling over land is much larger than that over ocean. These results are consistent with IPCC (1999) findings that the climate change caused by contrails is small and that detecting the aircraft specific contribution to global climate change is not possible now and presents a challenge for the future. 


\section{CONCLUSIONS AND DISCUSSION}

In this study, we evaluate the potential effect of contrail formation on the radiative forcing and climate impact around Taiwan using SUNYA regional climate model. In the simulation, the contrail radiative properties, including its coverage, particle effective radius, and solar and longwave optical thickness, were adopted from a contrail model by Chen et al. (2001). Radiative forcing for twelve types of dissipating and persistent contrails is examined, considering conditions with and without the diurnal cycle of contrail coverage.

For typical persistent contrail with diurnal cycle variation of contrail coverage, the daily mean solar and longwave radiative forcing are calculated to be 5.8 and $2.1 \mathrm{~W} \mathrm{~m}^{-2}$, respectively, at the top of atmosphere, while on the surface the respective values are 4.9 and $0.19 \mathrm{~W} \mathrm{~m}^{-2}$. The daily radiative forcing without diurnal cycle is about $2 / 3$ of these values. For dissipating contrails, the radiative forcing is much smaller. The results also suggest that the radiative forcing is dominated by the contrail coverage while the radiative properties play relatively minor role, mainly because of the more inhomogeneous spatial distribution of the former.

Because of the difficulty in linking the radiative forcing to climate changes on the regional basis, we have also conducted ensemble simulations to study the potential climate impact of the contrails. Three sets of experiments with different initial conditions were run. As expected, the presence of contrails would tend to warm up the contrail layer, with a maximum warming of $0.08^{\circ} \mathrm{C}$, while cooling of the layer immediately above is simulated. A small surface cooling is also simulated. Despite the robust warming of the contrail layer from the ensemble experiments, the model simulations also exhibit large (versus the contrail effect) internal variation in the local temperature.

Although the contrails may have global implications on the radiative forcing (Minnis et al. 1999), but given the small responses found in the present study, it is anticipated that, even on the regional and short-term (daily) basis, the climate response over the areas surrounding Taiwan would be small. However, the issue may become more important, given the projection of large increases in air traffic in this region (IPCC 1999). In addition, because of the important role of cirrus in affecting the radiation budget (Joseph and Wang 1999; McFarquhar et al. 2000), study of the contrail-cirrus cloud interaction is warranted (Seinfeld 1998; Boucher 1999).

Acknowledgements The research is supported by a grant (to SUNY-Albany) from the Office of Biological and Environmental Research, Office of Science, the U. S. Department of Energy.

\section{REFERENCES}

Boucher, O., 1999: Air traffic may increase cirrus cloudiness. Nature, 397, 30-31.

Chen, J.-P., W.-H. Lin and R.-F. Lin, 2001: Estimation of contrail frequency and radiative effects over the Taiwan area. TAO, 12, 155-178.

Gong, W. and W.-C. Wang, 2000: A regional model simulation of the 1991 severe precipitation event over the Yangtze-Huai River Valley, part II: model bias. J. Climate, 13, 93108.

IPCC, 1996: Climate Change 1995: The Science of Climate Change. In: J. T. Houghton, L. 
G. Meira Filho, B. A. Callander, N. Harris, A. Kattenberg and K. Maskell (Eds.), Cambridge University Press, Cambridge, UK.

IPCC, 1999: Aviation and the global atmosphere. In: J. E. Penner, D. H. Lister, D. J. Griggs, D. J. Dokken and M. McFarland (Eds.), Intergovernmental Panel on Climate Change. Cambridge University Press, pp 373.

IPCC, 2001: Working Group I, Third Assessment Report. Cambridge University Press, Cambridge. (in press)

Joseph, E. and W.-C. Wang, 1999: An interactive cirrus cloud radiative parameterization for global climate models. J. Geophys. Res., 104, 9501-9515.

Kiehl, J. T., J. J. Hack, G. B. Bonan, B. A. Boville, B. P. Briegleb, D. L. Williamson and P. J. Rasch, 1996: Description of the NCAR Community Climate Model (CCM3). NCAR Tech. Note, NCAR/TN-420+STR, National Center for Atmospheric Research, Boulder, $\mathrm{CO}$.

Liang, X.-Z. and W.-C. Wang, 1995: A GCM study of the climatic effect of 1979-1992 ozone trend. Atmospheric Ozone as a Climate Gas. In: W.-C. Wang and I.S.A. Isaksen , (Eds.), NATO ASI Series, 259-288, Springer-Verlag.

Lin, P. H., W.-S. Sun and J.-P. Chen, 2001: The inventory of civil aircraft emissions over Taiwan. $T A O, 12,39-60$.

McFarquhar, G. M., A. J. Heymsfield, J. Spinhirne and B. Hart, 2000: Thin and subvisible tropopause cirrus: Observations and radiative impacts. J. Atmos. Sci., 57, 1841-1853.

Minnis, P., U. Schumann, D. R. Doelling, K. M. Gierens and D. W. Fahey, 1999: Global distribution of contrail radiative forcing. Geophys. Res. Lett., 26, 1853-1856.

Reisner, J., R. M., Rasmussen and R. T. Bruintjes, 1998: Explicit forecast of supercooled liquid water in winter storms using the MM5 mesoscale model. Q.J. R. Meteorol. Soc., 124, 1071-1107.

Schroder, F., B. Karcher, C. Duroure, J. Strom, A. Petzold, F.-F. Gayet, B. Strauss, P. Wendling and S. Borrmann, 2000: On the transition of contrails into cirrus clouds. J. Atmos. Sci., 57, 464-480.

Seth, A. and F. Giorgi, 1998: The effects of domain choice on summer precipitation simulation and sensitivity in a regional climate model. J. Climate, 11, 2698-2712.

Seinfeld, J. H., 1998: Clouds, contrails and climate. Nature, 391, 837-838.

Wang, W.-C., M. P. Dudek, X. Liang and J. T. Kiehl, 1991: Inadequacy of effective $\mathrm{CO}_{2}$ as a proxy in simulating the greenhouse effect of other radiatively active gases. Nature, 350, 573-577.

Wang, W.-C., W. Gong and H. Wei, 2000: A regional model simulation of 1991 severe precipitation event over the Yangtze-Huai River Valley. Part. I: Precipitation and circulation statistics. J. Climate, 13, 74-92.

Wang, W.-C., I. S. A. Isaksen, J. Wang, M. Gauss and X.-Z. Liang, 2000: Atmospheric ozone as a climate gas: Studies concerning aircraft emissions. 105-119, in "Chemistry and Radiation Changes in the Ozone Layer". (Eds.) C. S. Zerofos, I. S. A. Isaksen, and I. Ziomas. NATO Science Series C: Mathematical and Physical Sciences, Vol. 557, Kluwer Academic Publishers, Dordrecht'Boston/London.

Xue, Y., M. J. Fennessy and P. J. Sellers, 1996: Impact of vegetation properties on U.S. summer weather prediction.J. Geophy. Res., 101, 7419-7430. 